Disponível em:

http://editora.unoesc.edu.br/index.php/race

RACE, Joaçaba, p. 157-184, Edição Especial, 2017

\title{
CONFLITOS NAS RELAÇÕES SOCIAIS DE TRABALHO NO CONTEXTO DA NOVA GESTÃO PÚBLICA À LUZ DA PSICODINÂMICA DO TRABALHO
}

Conflicts in the social relations at work in the context of the new public management in the light of the work psychodynamics

\section{Rafaela Gomes Aguiar}

E-mail: rafaela.gomes@uece.br

Mestre em Administração pela Universidade Estadual do Ceará; Especialista em Gerenciamento de Projetos pela Universidade de Fortaleza; Analista de Projetos no setor de Tecnologia da Informação na Universidade Estadual do Ceará.

\section{Ana Cristina Batista dos Santos}

E-mail: ana.batista@uece.br

Doutora em Administração pela

Universidade Federal do Rio Grande do Norte; Mestre em Administração pela Universidade Estadual do Ceará; Professora Assistente na Universidade Estadual do Ceará. Endereço para contato: Avenida Dr. Silas Munguba, 1700, Campus do Itaperi, 60741-000, Fortaleza, Ceará, Brasil.

Artigo recebido em 04 de agosto de 2017. Aceito em 13 de novembro de 2017. 


\section{Resumo}

No texto apresentam-se os resultados de uma pesquisa em que se teve o objetivo de compreender o fenômeno dos conflitos nas relações sociais de trabalho, em organizações públicas, no contexto da Nova Gestão Pública, sob as lentes da Psicodinâmica do Trabalho. A revisão de literatura aborda: as tipologias da administração pública: administração pública patrimonialista, administração pública burocrática, nova gestão pública; a lente teórica da Psicodinâmica do Trabalho e suas dimensões constituintes; e os conflitos nas relações de trabalho. Metodologicamente, realizou-se uma pesquisa qualitativa, com uso de entrevistas narrativas com 14 servidores da administração direta e da administração indireta de um estado do Nordeste brasileiro. Utilizou-se a técnica da análise dos núcleos de sentido para a compreensão das narrativas. Após a transcrição e categorização das entrevistas, os seguintes temas foram identificados: condições de trabalho, organização do trabalho, relações sociais de trabalho, medo, carga psíquica, doença/saúde, sofrimento/prazer e estratégias de defesa. Concluiu-se que os conflitos originários da relação sujeito-trabalho e das relações sociais, profissionais e afetivas que se desenrolam nos contextos de trabalho sob a Nova Gestão Pública compõem uma fonte de ansiedade, tensão, inquietação, medo e sofrimento, ao mesmo tempo que tal contexto e relações são palco da emergência de dimensões associadas ao prazer, como valorização, satisfação e reconhecimento, confirmando que os constructos prazer e sofrimento operam no real do trabalho de maneira inter-relacionada.

Palavras-chave: Administração pública brasileira. Conflitos. Psicodinâmica do Trabalho.

\section{Abstract}

The text presents the results of a research whose objective was to understand the phenomenon of conflicts in social relations of work, in public organizations, in the context of the New Public Management, under the lenses of Work Psychodynamics. The literature review addresses: the types of public administration: patrimonial public administration, bureaucratic public administration, new public management; the theoretical lens of the Work Psychodynamics and its constituent dimensions; and conflicts in labor relations. Methodologically, a qualitative research was carried out, using narrative interviews with fourteen employees of the direct administration and indirect administration of a State of Northeast Brazil. The technique of the analysis of sense nuclei was used to understand the narratives. After transcribing and categorizing the interviews, the following topics were identified: work conditions, work organization, social work relations, fear, psychic burden, disease/health, suffering/pleasure and defense strategies. It was concluded that the conflicts originating from the subject-work relationship and the social, professional and affective relations that unfold in the contexts of work under the New Public Management, constitute a source of anxiety, tension, restlessness, fear and suffering, at the same time in which such context and relations are the stage of the emergence of dimensions associated with pleasure, such as appreciation, satisfaction, 
recognition, confirming that the constructs pleasure and suffering operate in the real of work in an interrelated way.

Keywords: Brazilian public administration. Conflicts. Psychodynamics of Work.

\section{INTRODUÇÃO}

A gestão pública é um campo de pesquisa e de prática de grande interesse por parte de pesquisadores e núcleos de pesquisa no Brasil. Uma compreensão contemporânea sobre o campo, especialmente no que diz respeito ao modo de gestão praticado no seio das instituições públicas de Estado, nas suas mais variadas instâncias, exige um resgate das mudanças pelas quais ele vem passando, no decorrer da sua trajetória de reformas.

Na administração pública brasileira, há pelo menos três fases já sistematizadas na literatura numa perspectiva histórica: a administração patrimonialista, a administração burocrática, e a nova gestão pública (NGP), também conhecida como administração pública gerencial, reforma gerencial ou, simplesmente, gerencialismo. Há, ainda, uma fase mais atual denominada novo serviço público, que busca reunir práticas gerenciais dos setores público e privado (BRESSER-PEREIRA, 2001; SECCHI, 2009; ANDION, 2012; CARDOSO, 2016).

Tais modelos de gestão pública representam cada qual um determinado período histórico. No entanto, tem sido debatido que não houve uma substituição plena dos modelos anteriores pelos novos, de modo que características de todos os modelos podem ser encontradas na administração pública atual (PAES DE PAULA, 2005; SECCHI, 2009). Neste trabalho parte-se do pressuposto de que no cotidiano do trabalho do serviço público há uma tendência a não se observar o modelo puro desses tipos de administração, podendo-se inferir que, na NGP, há uma mistura de elementos dos modelos patrimonialista e burocrático.

Um aspecto da organização do trabalho público que se destaca é o fenômeno dos conflitos nas relações sociais de trabalho que emergem no cotidiano de trabalho, especialmente em tempos de mudanças nos modelos de gestão, como na contemporaneidade, especialmente em contextos nos quais se percebem resquícios dos antigos modelos.

Este trabalho não aborda o fenômeno dos conflitos apenas do ponto de vista dos comportamentos individuais e grupais manifestos, mas admite que há outra dimensão desse fenômeno, individual, subjetiva, que se constitui como conflito psíquico, psicoafetivo. Contudo, entende-se que eles são forjados e emergem da relação homem-trabalho, a qual inclui a relação do homem com ele mesmo e com os outros. 
Nesse sentido, a lente de análise escolhida foi a Psicodinâmica do Trabalho (PDT), corrente teórica emergente na França, na década de 1970, a partir dos trabalhos de Christophe Dejours. Essa lente teórica volta-se para a observação de conflitos psíquicos suscitados pela experiência do homem com seu trabalho (SICHÈRE, 2010), sendo "psicodinâmica" um termo que se refere aos estudos dos movimentos psicoafetivos gerados pela evolução dos conflitos intersubjetivos e intra-subjetivos existentes no trabalho (BUENO; MACÊDO, 2012).

Na corrente dejouriana, a PDT propõe estudar duas grandes principais dimensões (de contexto e de conteúdo) a fim de compreender a relação trabalhador-organização do trabalho. A primeira é composta pelas dimensões de contexto: condições de trabalho, organização do trabalho e relações sociais de trabalho. A segunda é composta pelas dimensões de conteúdo: carga psíquica, vivências de prazer-sofrimento, estratégias de enfrentamento ou defensivas e reconhecimento (DEJOURS; ABDOUCHELI; JAYET, 1994; MENDES, 2007; BUENO; MACÊDO, 2012; SILVA; LAVNCHICHA, 2015).

Elegeu-se uma das dimensões de contexto da PDT para estudo: relações sociais de trabalho. Essa escolha parte do pressuposto de que o contexto de mudanças tende a alterar o ambiente de trabalho, reconfigurando as relações entre chefias e subordinados, entre pares, entre servidores e cidadãos - os "clientes" do serviço público (SICHÈRE, 2010). O foco nas relações sociais de trabalho se justifica por sua referência às interações de diversas ordens: hierárquicas, grupais (intra e intergrupos) e externas (clientes, usuários, parceiros, fornecedores e consumidores). Contém, ao mesmo tempo, vivências de trabalho dos servidores públicos no contexto de transformações inerentes aos processos de mudança em curso (MACÊDO; MENDES, 2004).

Bueno e Macêdo (2012) mostram que, no Brasil, em áreas como a Administração, o interesse em utilizar a PDT para estudar, por exemplo, sobre a identidade do trabalhador e suas relações é recente, manifestando-se pela criação de: laboratórios e grupos de pesquisas; cursos de extensão; e disciplinas relacionadas ao comportamento organizacional, aos recursos humanos, à psicologia das organizações, às relações de trabalho e aos estudos críticos em organizações, oferecidas em universidades por todo o País.

Há um avanço significativo não somente quanto ao interesse em produzir conhecimento científico com a lente da PDT, mas, antes de tudo, há uma agenda voltada para a ação. Preconiza-se um trabalho conjunto entre pesquisador e sujeito, propondo novas concepções e a emergência de um saber capaz de reconstruir e de transformar a realidade (MERLO; MENDES, 2009). Contudo, Mendes, Araújo e Merlo (2011) ressaltam que ainda são poucos os estudos brasileiros na perspectiva da PDT como campo de intervenção. Destacam que é um campo pertinente para estudar, com pos- 
sibilidades de ampliação não apenas como uma teoria e um método de pesquisa, mas também como uma prática profissional.

Almejando contribuir para essa pauta de pesquisa emergente, este estudo contribui para o crescimento de estudos que usam a PDT como lente analítica (MERLO; MENDES, 2009) no campo da Administração, privilegiando a Administração Pública. Em levantamento bibliométrico focando o período de 1996 a 2009, foram encontrados 79 artigos, além de dissertações, teses e outras publicações, utilizando a PDT como referência. Merlo e Mendes (2009) identificaram que apenas 6,33\% dos estudos foram na área de Administração.

Mais recentemente, Silva e Lavnchicha (2015) observou que nos últimos 10 anos, no panorama brasileiro, as temáticas estudadas em PDT foram as mais variadas. No entanto, embora houvesse registros nos programas de pós-graduação em Administração, foi notório que tais estudos ainda eram mais recorrentes nos programas de Psicologia, assim como os estudos vinculados à Ergonomia foram facilmente encontrados nos programas de Engenharia, sobretudo na Engenharia de Produção (SILVA; LAVNCHICHA, 2015).

Sabe-se que a Administração é um campo multidisciplinar, que se relaciona com diversas outras áreas das Ciências Sociais e que tem como uma de suas principais variáveis os modelos de gestão. Sabe-se, ainda, que a Administração é considerada pelos pesquisadores como um campo relevante para a investigação exatamente por interagir com outras ciências, permitindo diferentes visões das relações indivíduo-trabalho, objetividade-subjetividade, regulação social e mudança social, assim como diferentes possibilidades de aplicação do método científico (SANTANA; GOMES, 2007).

Dessa forma, argumenta-se que tão importante quanto compreender as relações sociais de trabalho em contextos organizacionais da gestão pública é destacar o processo de interdependência entre diversos campos do saber que esse objeto de estudo suscita, apontando a importância da permeabilidade das fronteiras (PECI; ALCADIPANI, 2004). Logo, observa-se que em razão da recente emergência da NGP e da quase inexistência de estudos sobre ela à luz da PDT, o tema conflitos nas relações sociais de trabalho, em virtude da implementação de tecnologias gerencialistas nas organizações públicas, mostra-se bastante pertinente (MERLO; MENDES, 2009; MENDES; ARAÚJO; MERLO, 2011).

A relevância teórica da pesquisa e as lacunas que ela visa a preencher se relacionam a três aspectos: à escassez de estudos que articulem o tema conflitos nas relações de trabalho ao contexto da NGP; à pouco expressiva produção científica brasileira sobre a PDT no campo da Administração; à quase inexistente produção científica que articule NGP e PDT. O objetivo com o estudo foi compreender o fenômeno 
dos conflitos nas relações sociais de trabalho em organizações públicas no contexto da NGP, sob as lentes da PDT. Por meio do Esquema 1 é possível observar graficamente o desenho teórico-metodológico da pesquisa.

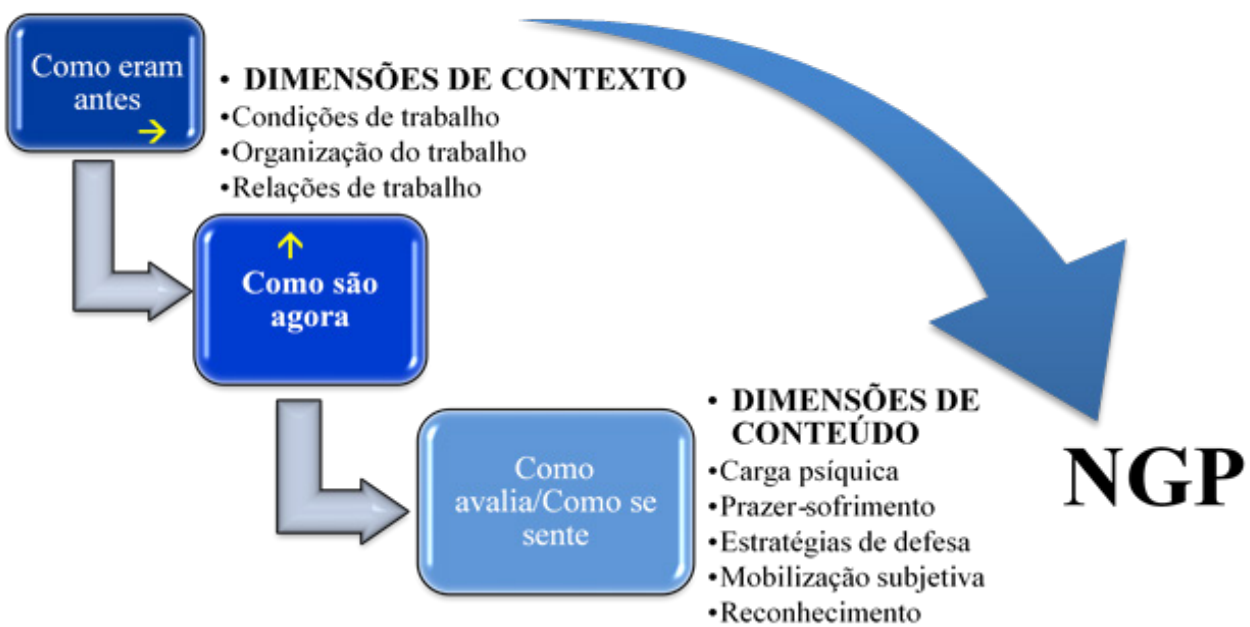

Fonte: os autores.

O ponto de vista adotado é o de que a NGP não é simplesmente um modelo gerencial. Ela constitui uma dimensão de um processo amplo de reestruturação dos setores públicos, provocando mudanças significativas no ambiente de trabalho. A sistematização e análise dos conflitos nas relações de trabalho tiveram como objeto empírico um estado do Nordeste brasileiro, em particular os setores públicos que passaram pela implantação da NGP. Logo, o campo da pesquisa escolhido foram as entidades públicas que aderiram à NGP, nesse Estado.

\section{ADMINISTRAÇÃO PÚBLICA BRASILEIRA}

O primeiro modelo de administração pública no Brasil, o patrimonialista, baseado nos modelos de Estados Absolutistas, firmou-se mais fortemente nos séculos XVII e XVIII, perdurando durante todo o Período Colonial, Imperial até o final da 
Primeira República. O Estado brasileiro era autoritário e oligárquico, sedimentado no seio de uma economia agrícola mercantil e de uma sociedade senhorial recém-saída do escravismo (BRESSER-PEREIRA, 2001). O patrimonialismo era uma forma de dominação política sem diferenciação nítida entre as esferas pública e privada. A administração era autocentrada, e a sociedade não tinha a possibilidade de interferir nos destinos dos recursos públicos (WEBER, 1999).

São características do modelo patrimonialista: o nepotismo, o clientelismo, a corrupção, a ineficiência, o improviso, a falta de profissionalismo, a ausência de métodos de trabalho, as falhas de planejamento e a dilapidação do patrimônio público, entre outras. $\mathrm{O}$ aparelho estatal era constituído por uma gestão estritamente firmada pela tradição, na qual o gestor tomava as decisões conforme sua vontade e suscetível a se deixar influenciar por preferências pessoais (SECCHI, 2009).

Com as transformações históricas, em suas manifestações socioeconômicas e implicações políticas, a administração pública patrimonial sofreu inúmeras críticas no Brasil e no mundo, o que favoreceu a pressão dos adeptos dos ideais democráticos pela sua profissionalização, atendendo aos princípios constitucionais. Nesse movimento, e com o avanço do capitalismo, a sociedade e o mercado se distinguiram do Estado, facilitando a implantação do modelo burocrático (BRESSER-PEREIRA, 2001).

Na Era Vargas (1930 a 1945), pode-se identificar os primeiros ensaios de profissionalização do serviço público brasileiro por meio da tentativa de superação de um momento coronelista oriundo do período pré-burocrático (FAORO, 2001). Iniciava-se uma nova fase com a introdução do modelo burocrático ou racional-legal.

Em 1933, é criado o Departamento de Administração do Serviço Público (DASP) que se transformou no símbolo da busca de um Estado moderno e de uma burocracia pública profissionalizada. O ano 1936 é o marco da introdução dessa nova forma de administração pública, formada pelos princípios do tipo ideal de burocracia de Max Weber: a impessoalidade, o formalismo, a profissionalização, a ideia de carreira e a hierarquia funcional. Do ponto de vista prático, o departamento foi responsável pela organização do Estado quanto ao planejamento, orçamento e administração de pessoal. O interesse público e o controle a priori passam a determinar essa fase (BRESSER-PEREIRA, 2002).

O modelo burocrático tem três características principais: o profissionalismo, com a meritocracia como critério de justiça e diferenciação, a separação entre propriedade pública e privada, o trabalho remunerado, a divisão racional das tarefas e a separação dos ambientes de vida e trabalho; a impessoalidade, em que a relação entre membros da organização e entre a organização e o ambiente externo está baseada 
em regime de autoridade clara, centrada na estrutura de cargos; e a formalidade, que requer a observância de deveres e responsabilidades pelos membros da instituição, a legitimidade de uma hierarquia administrativa, as documentações escritas dos procedimentos, a padronização dos processos decisórios e a formalização dos canais de comunicação (WEBER, 1999; SECCHI, 2009).

Contudo, a administração pública burocrática se deparava com o surgimento de uma série de problemas que a doutrina convencionou chamar de disfunções da burocracia (anomalias e imperfeições) (SECCHI, 2009). O excesso de burocratização, de formalismo e de despersonalização originou as disfunções da burocracia, estas fortemente marcadas por: elevado apego às normas; excesso de formalismo e papelório; resistências às mudanças; superconformidade às rotinas e procedimentos; nível mínimo de desempenho; categorização como base do processo decisorial, dificuldades e conflito no atendimento a clientes.

Em meio à insatisfação crescente com a burocracia, movimentos engajados com a construção de um modelo centrado em resultados e na eficiência das ações no segmento público, visando à primazia e à responsabilidade social, faziam pressão para o surgimento de um novo modelo de administração pública. Nos anos 1980 se inicia uma revolução na administração pública dos países centrais, em direção a uma administração pública gerencial, dando espaço ao surgimento de teorias que visavam propor novas formas de gerenciar o aparelho do Estado (ABRUCIO, 2007; BRESSER-PEREIRA, 2001).

Em 1995, no governo do então Presidente da República Fernando Henrique Cardoso (1994-2002), inicia uma reforma gerencial, marco inaugural de uma nova concepção de gestão pública, a qual ganha cada vez mais espaço com a implementação do Plano Diretor da Reforma do Aparelho do Estado (PDRAE), sob a coordenação de Luiz Carlos Bresser-Pereira, Ministro da Administração Federal e da Reforma do Estado (MARE). Pautado na eficiência, eficácia e efetividade do aparelho do Estado, o PDRAE tinha como objetivo assegurar o cumprimento das diretrizes por ele estabelecidas e obedecer às estratégias concebidas em três dimensões: institucional-legal, cultural e gerencial (BRASIL, 1995). Inicia-se uma nova fase reformista, agora com o propósito de instituir uma administração gerencial.

O modelo da NGP busca apoiar de forma substancial o aumento da igualdade no acesso aos serviços públicos, bem como a melhoria da eficiência dos serviços prestados. Utiliza o planejamento estratégico como umas das ferramentas de gestão dos projetos a serem desenvolvidos pelo poder público, a maior autonomia gerencial, a 
construção de indicadores de desempenho e, acima de tudo, a avaliação dos resultados alcançados (HOOD, 1991).

A descentralização do poder e da autoridade dos gestores, bem como a divisão e horizontalização das organizações caracterizam mudanças trazidas pela NGP. O objetivo é assegurar a real mudança das regras gerais para os resultados, enfatizando a redução de custos, a eficácia e a eficiência dos aparelhos de Estado e propondo a clientelização dos cidadãos (FONSECA; PEREIRA; GONÇALVES, 2015).

Dentro dessa conjuntura, e por ser algo novo, a NGP sofreu oposição por parte da opinião pública e trouxe muitas mudanças, posturas e discursos, gerando descontentamento por parte dos servidores e obstáculos à sua implementação (ANDION, 2012). Algumas críticas em relação às mudanças propostas pelo modelo da NGP levam a sociedade e os servidores a repensá-la (EVARISTO; BATISTA-DOS-SANTOS, 2015). Uma das críticas é a forma de implementação ou de operacionalização das práticas suscitadas pelo modelo da NGP, sobretudo a atenção especial à especialização, fragmentação e mercantilização como formas de funcionamento dos serviços da administração pública (SIMIONE, 2014). A fragmentação, conforme argumenta Simione (2014, p. 557):

Provoca uma redução drástica do centro de atenção dos problemas. A fixação de objetivos, a avaliação do desempenho e a responsabilidade vertical prejudicam a integração horizontal. Esse modelo torna a coordenação mais complexa, pois requer muitas vezes a reconciliação de conflitos entre agências com posições discordantes, ofusca a responsabilidade para determinadas questões e enfatiza a necessidade do governo em reforçar o controle central.

As críticas construídas ao modelo da NGP podem ser entendidas como um insucesso desta em perceber que os arranjos administrativos e de gestão nela propostos não estão apenas destinados ao oferecimento de serviços públicos, mas também aos que institucionalizam valores administrativos profundos e que são, portanto, em alguns aspectos, inseparáveis da própria essência do funcionamento do Estado e das suas respectivas organizações (LODGE; GILL, 2011). As críticas realizadas ao novo modelo gerencial não dizem respeito à volta ao modelo burocrático, mas, sim, à correção do gerencialismo puro no sentido de incorporar novos significados. Evaristo e Batista-dos-Santos (2015, p. 13), baseados nos estudos de Abrucio (2007) e Guimarães (2000), apontam sugestões para a melhoria do modelo, como: 
Profissionalizar os servidores estatais; trazer profissionais do mercado para agregar conhecimento; convencer os atores da necessidade da implementação da NGP; efetivar uma visão de longo prazo; possuir entidades e equipamentos reguladores eficazes; romper com os modelos tradicionais; adotar novos modelos de gestão, organização e divisão do trabalho; construir alianças; parcerias e redes.

Gomes (2011) afirma a tentativa da NGP de romper com os procedimentos burocráticos em demasia, afastando-se do modelo weberiano e propondo o modelo que se baseie em eficiência, eficácia, efetividade e competitividade nas organizações públicas. Nesse sentido, o Governo usaria mecanismos competitivos entre as organizações com a finalidade de promover melhores resultados dos serviços prestados aos cidadãos. A avaliação dos resultados ganharia predominância em relação à execução das atividades, conforme as normas estabelecidas. Isso significa que, em vez de priorizar o seguimento de normas e processos burocráticos, enfatiza a satisfação do cidadão, com qualidade e eficiência dos procedimentos adotados nos serviços públicos.

Diante dessas críticas, dando espaço ao surgimento de princípios que visam propor novas formas de gerenciar o aparelho do Estado, passou-se a buscar o resgate do usuário do serviço público como cidadão, e não como consumidor. Dessa busca, questões ligadas à transparência, participação, equidade e justiça, surgem como abordagem para o Serviço Público, ou Public Service Orientation (PSO), no contexto britânico, e o Novo Serviço Público, nos Estados Unidos. Para Cardoso (2016, p. 80), “a orientação para o serviço público, tem como fonte de preocupação a qualidade do serviço público e a busca pela participação e responsabilização dos cidadãos usuários do serviço público.”

Este trabalho parte do pressuposto que tais mudanças no modelo de gestão, na concepção de Estado e de Governo, vão implicar transformações nas relações cotidianas de trabalho dentro dos órgãos, favorecendo a emergência de conflitos, em face do novo. É nesse espaço de problematização do objeto, lançando luz para o que acontece nas relações de trabalho nessa "passagem amalgamada” de modelos gerenciais, que esta pesquisa se orientou pelas lentes da PDT, na busca da compreensão da dinâmica intersubjetiva, diante dos conflitos gerados quando do confronto entre o desejo do sujeito trabalhador e os modelos de organização e gestão dos trabalhos implantados. 


\section{PSICODINÂMICA DO TRABALHO}

Apsicodinâmica do trabalho é compreendida a partir de conceitos que examinam o relacionamento entre a organização do trabalho e o trabalhador, considerando duas dimensões: as de contexto e as de conteúdo. Conforme as obras de Dejours (1992, 2004, 2011) e Dejours e Abdoucheli e Jayet (1994), das dimensões de contexto e de conteúdo da PDT resultaram vários elementos que influenciaram os indicadores do sofrimento ligado ao trabalho. As dimensões de contexto (condições de trabalho, organização do trabalho e relações sociais de trabalho) representam uma espécie de "cenário" em que os aspectos psicodinâmicos são forjados e emergem. As dimensões de conteúdo, por sua vez, expressam os conceitos psicodinâmicos propriamente ditos e variam em torno dos seguintes constructos: carga psíquica, vivências de prazer-sofrimento, estratégias defensivas ou de enfrentamento, reconhecimento, entre outros.

A PDT considera que o ambiente laboral é o lugar tanto do sofrimento quanto do prazer, o qual hospeda as situações dinâmicas relacionadas à relação homem-trabalho. O trabalho é produto dessa dinâmica, das relações e das ações dos trabalhadores. Nessa perspectiva, a PDT tem por objetivo o estudo das relações entre condutas, comportamentos, experiências de sofrimentos e de prazeres vividos, por um lado, e a organização do trabalho e as relações sociais de trabalho, por outro (DEJOURS, 2004).

Na visão de Dejours (1994), a organização do trabalho, inserida nas dimensões de contexto, engloba a divisão do trabalho, o conteúdo dos procedimentos, todas as dimensões que compreendem a hierarquia e as relações de poder, as formas de comando e as divisões das responsabilidades. É constituída por elementos formais e informais que devem ser cumpridos (o trabalho prescrito), que representam os modelos de gestão existentes e implementados para o funcionamento do trabalho (MENDES; FERREIRA, 2008).

Silva e Lavnchicha (2015, p. 6) destaca que a organização do trabalho "é o resultado de uma negociação que envolve tanto o conteúdo das tarefas quanto as relações humanas de trabalho.” Nesse sentido, o vínculo com o trabalho não é estritamente técnico, cognitivo ou físico, mas é, sobretudo, um vínculo intersubjetivo e social.

As relações sociais de trabalho são constituídas por elementos interacionais que expressam as relações interpessoais presentes no cenário de trabalho e caracterizam sua dimensão social. Os elementos que integram essa dimensão são os seguintes: interações hierárquicas - subordinados, chefias imediatas e superiores; interações coletivas intra e intergrupos - membros da equipe de trabalho, membros de outros gru- 
pos de trabalho; e interações externas - usuários, consumidores, parceiros, representantes institucionais (MACÊDO; MENDES, 2004; MENDES; FERREIRA, 2008).

A relação com o trabalho ou com os outros trabalhadores tende a se tornar a principal referência das pessoas. O sentimento de identidade social é fortemente ancorado na relação profissional. Dejours (1992) entende que esses laços criados pela organização do trabalho são, por vezes, desagradáveis e, até, insuportáveis. Mas, é por meio do trabalho que o sujeito se engaja nas relações sociais nas quais visualizará as questões herdadas de seu passado e sua história afetiva (DEJOURS, 2004).

O trabalho enquanto atividade é um processo de confronto e de diálogo. De um lado, há um indivíduo que busca satisfação para suas necessidades, desejos e sonhos; de outro, há as circunstâncias de trabalho que oferecem um modelo de produção, de um modo geral padronizado, impactando as percepções desse trabalhador em relação a todo o contexto de trabalho. O conteúdo de trabalho, o modo como ele é coordenado e as relações que se afirmam nesse ambiente trazem, muitas vezes, intimidação e, além de dificultarem o bom funcionamento das atividades, criam um contexto no qual o sofrimento passa a ser também um produto do trabalhar (GOMES, 2011).

Sabe-se, porém, que o sofrimento é um traço significativo no processo de trabalho, pois, além de ser uma vivência de afetos dolorosos, é um mobilizador para as modificações das circunstâncias que fazem sofrer, quando é ressignificado pelo uso eficaz de estratégias de mediação favorecidas pelo contexto de trabalho (MENDES; FREITAS; AUGUSTO, 2014).

Para Silva e Lavnchicha (2015), as premissas da PDT estão centradas nas possibilidades do desenvolvimento dos sujeitos a partir das relações no trabalho. Segundo Sznelwar, Uchida e Lancman (2011), é preciso considerar que não existe um sujeito isolado; ele existe e se constitui numa relação intersubjetiva na qual o trabalho é elemento inseparável. Dejours, Abdoucheli e Jayet (1994) concordam que trabalhar não é apenas uma relação entre o sujeito e suas tarefas. O trabalho pode provocar medos e ansiedades diversas, relacionadas tanto ao ambiente físico quanto à regularidade do cotidiano do trabalho e às relações humanas, o que exige o desenvolvimento de estratégias defensivas na tentativa de preservar a saúde mental e garantir a produtividade, as quais passam, quase sempre, pela relação com o outro.

\section{PROCEDIMENTOS METOdOLÓGICOS}

A metodologia de pesquisa em PDT está apoiada na epistemologia das ciências históricas e hermenêuticas, que recorre à técnica da interpretação. O seu objetivo 
é a elaboração da vivência do sofrimento no trabalho à medida que permite desvendar as vivências subjetivas e intersubjetivas dos sujeitos em relação à organização do trabalho. Perceber aquilo que, na organização do trabalho, é fonte de pressões, de dificuldades, de desafios passíveis de ocasionar sofrimento, mas também prazer (DEJOURS; ABDOUCHELI; JAYET, 1994; DEJOURS, 2004).

A pesquisa em PDT lida com dimensões teórico-empíricas, como carga psíquica, prazer-sofrimento, estratégias de defesa, que, mesmo sendo fruto ou estando associadas a uma vivência objetiva no mundo do trabalho, são vividas pelo sujeito na dimensão subjetiva, de maneira não mensurável e não quantificável. Logo, a abordagem qualitativa se mostra pertinente para tratar de tal dinâmica inscrita na relação interdependente entre objetividade e subjetividade, que pode ser elaborada pelo sujeito por meio da fala livre, da liberdade de expressão e autonomia, no momento em que o sujeito nomeia o que sente (DEJOURS, 1992).

Quanto ao seu objetivo, desenvolveu-se uma pesquisa exploratório-descritiva. A estratégia utilizada nos procedimentos técnicos e a abrangência empírica ocorreram por amostragem de caso único, do tipo institucional. De acordo com Pires (2008), essa abordagem tem a vantagem de permitir um maior aprofundamento e maior riqueza na coleta de dados, além de um universo de análise que se apresenta ao analista de forma não parcelada como sendo passível de uma apreensão em sua totalidade.

Stake (2013) destaca a importância da escolha do caso para o entendimento do fenômeno em estudo, a qual deve estar focada na busca por aquele caso que oferece maior espaço de aprendizagem sobre tal fenômeno. Assim, escolheram-se para este estudo as secretarias de um estado do Nordeste brasileiro que implantaram a NGP, porque estas se constituem de um processo amplo de reestruturação dos setores públicos, provocada por mudanças significativas advindas do modelo da NGP.

Quanto à diversidade de localidades onde o fenômeno ocorre, foi escolhida a técnica de diversificação interna ou intragrupo, em que se alcançaram as diferenças em um conjunto homogêneo de sujeitos ou situações. Cada uma delas é uma investigação específica dentro de um caso mais completo, buscando-se, assim, analisar o que é comum e o que é peculiar ao caso (STAKE, 2013; PIRES, 2008).

Para a definição do número de entrevistados, adotou-se o critério de saturação empírica dos dados, que é definida como um fenômeno pelo qual, depois de certo número de entrevistas, o entrevistador tem a noção de nada recolher de novo, ou diferente, para justificar uma ampliação do campo empírico quanto ao objeto da pesquisa (PIRES, 2008). A saturação empírica foi atingida num total de 14 entrevistas, realizadas com gestores e subordinados ligados às secretarias do estado pesquisado que 
vivenciaram ou que vivenciam o contexto de transformações, inerentes ao processo de mudança em organizações públicas.

A participação nas entrevistas ocorreu de forma voluntária. A maioria dos participantes entrevistados tinha mais de 25 anos de tempo de serviço público, o que veio a enriquecer muito a pesquisa, e apenas dois entrevistados possuíam menos de 20 anos de tempo de serviço. As entrevistas ocorreram em dois meses, e, com o consentimento dos entrevistados, foi utilizado um aparelho para gravação, com posterior transcrição das falas, visto que a PDT privilegia a fala do indivíduo (MENDES, 2007).

Considerando o potencial da fala, a técnica de coleta de dados utilizada na pesquisa foi a entrevista narrativa, pela qual emergiram histórias de vida entrecruzadas no contexto institucional, em que as pessoas lembraram o que aconteceu, colocaram a experiência em uma sequência, encontrando possíveis explicações para os eventos e se dirigindo a acontecimentos concretos em um lugar e em um tempo determinado.

Para o entendimento do discurso dos servidores públicos entrevistados, foi utilizada a técnica de análise e interpretação dos núcleos de sentido (ANS). Para Mendes (2007, p. 72), “[...] a ANS consiste no desmembramento do texto em unidades, em núcleos de sentido formados a partir da investigação dos temas psicológicos sobressalentes do discurso.” Essa técnica de análise qualitativa possibilita o agrupamento do conteúdo latente e manifesto do texto, baseando-se na construção de núcleos de sentido, concedendo suporte às interpretações dos temas que são categorizados pelo critério de semelhança de significado semântico, lógico e psicológico. Por razões de espaço, as falas não são socializadas no texto, mas são feitas menções aos entrevistados que referenciam a análise, pela forma como foram codificados no processo de categorização das entrevistas (p. ex.: E1, E2, E3, etc.).

\section{ANÁLISE E DISCUSSÃO DOS RESULTADOS}

Os seguintes temas foram identificados: condições de trabalho, organização do trabalho, relações sociais de trabalho, medo, carga psíquica, doença/saúde, sofrimento/prazer e estratégias de defesa.

As condições de trabalho são estabelecidas por elementos estruturais presentes no ambiente de trabalho e caracterizam sua infraestrutura, apoio e práticas administrativas (MENDES; FERREIRA, 2008). No campo pesquisado, as condições de trabalho são positivamente percebidas pelos funcionários. Outro reconhecimento de grande importância foi a chegada da modernização tecnológica, promovendo inovações, agilidade nos processos de trabalho e um bom desenvolvimento profissional. 
E4 e E7 relataram satisfação nas mudanças de práticas administrativas, consagradas como “ambiente culto”, costumes ou normas, na padronização dos ambientes físicos do Estado, nos meios de transporte e também nas reestruturações físicas do ambiente de trabalho quando houve a quebra de paredes que dividiam os ambientes, proporcionando maior interação entre os colegas e chefias, donde se percebe a interação entre as dimensões de contexto da PDT: condições de trabalho, organização do trabalho e relações sociais de trabalho. Assim, um aparentemente simples derrubar de paredes se constituiu em uma alteração do modus operandi de cada trabalhador, bem como em suas relações sociais de trabalho.

A organização do trabalho é constituída de elementos objetivos, subjetivos e sociais, todos dotados da capacidade de gerar imprevistos, constrangimentos psíquicos e organizacionais, tratando-se de um conjunto complexo e interativo de forças que não pode ser inteiramente apropriado por prescrições. Em face ao real do trabalho, as mudanças ocasionadas nos ambientes físicos foram conduzidas com grandes dificuldades para os entrevistados E2, E3 e E8. Uma delas foi a extinção do órgão em que trabalhavam e a criação de uma empresa virtual, que passou a abrigá-los, deixando-os completamente abandonados. Isso gerou nos trabalhadores efeitos como: mudança física, sacrifícios, falta de motivação no dia a dia de trabalho, obrigação de conviver com a insegurança e sensação de abandono.

Esses efeitos são causadores de conflitos pessoais, grupais e organizacionais, que têm como principais causas: as mudanças, os recursos limitados, os desentendimentos entre metas e objetivos, a falta de comunicação e a incapacidade de sintonia entre setores. No entendimento de Silva e Lavnchicha (2015), as condições de trabalho e os sintomas provocados por suas alterações agem sobre o corpo, ocasionando vivências de prazer e/ou sofrimento, sendo geradoras de desgaste, envelhecimento e doenças no trabalhador.

As relações sociais de trabalho são constituídas por elementos interacionais que expressam as relações interpessoais presentes no cenário de trabalho (MACÊDO; MENDES, 2004). Identificou-se que os entrevistados E11 e E12 não sentiram dificuldades de relacionamento e que lutavam para manter o ânimo e boas amizades para seguirem com suas atividades, mesmo diante de grandes desafios que pareciam difíceis de serem superados, por vezes usando a estratégia de se adaptarem para sobreviver às mudanças.

Por outro lado, emergiram conteúdos que destacam os aspectos negativos nas relações. O entrevistado E5 revelou enfrentar dificuldades de relacionamentos como: vaidades pessoais, confronto pessoal, competências enaltecidas e embates internos em 
relação à aceitação de métodos de trabalhos implantados e à forma como eram cobrados. E4 apontou, ainda, existirem pessoas que odiavam a forma como ele trabalhava (informações verbais).

Qualquer relação de trabalho envolve pessoas, consequentemente, diferentes valores, crenças e princípios. Dejours (1992) entende que os laços criados pela organização do trabalho são, por vezes, desagradáveis e, até, insuportáveis, muitas vezes provocando clima de competição. Para E10, as discussões provocadas por questões de favores no trabalho foram a causa de conflitos explícitos nas relações, em que o sujeito, por questões éticas, por estar em desacordo com seu superior a respeito do que estava acontecendo, recusava-se a executar, utilizando a estratégia do afastamento para não entrar em atrito direto com o superior. Constatou-se processos que deixam os indivíduos incomodados com situações malresolvidas (E1), presos à ideia de segurança e estabilidade (E6), o que pode vir a transformar a organização numa prisão psíquica (DEJOURS, 1992).

Observou-se falta de interesse por parte dos “mais antigos” em relação aos novatos e falta de respeito às hierarquias, por parte de alguns subordinados, desvelando sobreposição do individualismo ao coletivo. E4 ainda enfatizou o conflito de gerações como a causa de problemas ou situações conflituosas, muitas vezes prejudiciais ao ambiente de trabalho.

O medo das mudanças se destacou como uma das principais razões de incômodos no cotidiano dos servidores entrevistados. As mudanças eram percebidas como ameaças e dificuldades que originavam os mais diversos tipos de medo. Dejours, Abdoucheli e Jayet (1994) concordam que o trabalho pode provocar medos e ansiedades diversas relacionadas tanto ao ambiente físico quanto à forma como o trabalho é organizado no cotidiano e às relações sociais de trabalho que ocorrem no contexto da organização. Verifica-se, portanto, o clima de instabilidade já existente entre os servidores entrevistados, talvez levados pela sua própria insegurança. Tal situação interfere no relacionamento social e cria tensões nos trabalhadores. Essas tensões são, muitas vezes, dolorosas de serem vividas psicologicamente e afetivamente, chegando a se cristalizarem em conflitos interpessoais.

E2 relatou que, diante das mudanças causadas pela organização, havia pessoas com medo do não acolhimento nas novas relações sociais de trabalho, que se revoltavam com as interferências políticas e passavam a reagir com mais inquietação. Já E3 e E6 se sentiam receosos diante dos novos desafios que se apresentavam. E3, por se sentir desprotegido, com pavor e com mais dificuldades de administrar as mudan- 
ças, buscou ajuda externa para aceitar melhor as mudanças que estavam acontecendo na organização do trabalho.

O temor das influências políticas, o medo de mudar o status quo e o pavor do que estava por vir causavam nos servidores insegurança e medo. Em seu discurso, E8 demonstrou apreensão, medo de não ser inserido no cotidiano do trabalho, temor e incertezas dos direcionamentos que receberia no seu local de trabalho. Para ele, as mudanças são tanto positivas quanto negativas. Ainda assim, questiona-se com preocupação sobre o futuro da organização. E11 explicou que, inicialmente, reagia tentando entender as mudanças que estavam acontecendo. Disse também ter presenciado, constantemente, situações de terror, principalmente com a chegada de servidores conhecidos por serem maldosos.

Para Mendes (2007), os sentimentos de desânimo, tensão emocional, ansiedade, sobrecarga, estresse, insegurança e cansaço são possíveis sinais de sofrimento no trabalho. Interessante observar que E3 admite que o processo de mudança era muito ruim e lhe fazia mal, ao ponto de lhe mobilizar a tomar providências pessoais sobre isso, em termos de tratamento psicológico. Ela decidiu, então, aceitar as mudanças e lidar de maneira tranquila.

E5 e E9, quando se referiam a gestões da época da NGP, relataram que o sofrimento era sentido nas cobranças excessivas por resultados, que os deixavam apreensivos e com a sensação de estarem sendo monitorados. Embora esse sofrimento, às vezes, não fosse verbalizado, ele interferia no comportamento do servidor e podia ser percebido por meio das demonstrações de inquietação, de agitação, de irritabilidade e de baixa capacidade de concentração. Nas relações sociais de trabalho, as cobranças no contexto de trabalho, em tempos de NGP, eram causas de conflitos internos entre chefias e subordinados, quando se tinha a figura do chefe autoritário (E9). Mesmo assim, E9 disse gostar da maneira personalista do governante, pois trazia resultados esperados para o Estado.

As mudanças organizacionais são percebidas pelos servidores como um processo de ruptura com o modelo anterior. Consequentemente, são enfrentadas com resistência e dificuldade. Essas dificuldades encontradas pelos indivíduos estão diretamente relacionadas ao sofrimento, que é ocasionado por vivências de afetos dolorosos. Isso ocorre a partir das tentativas de equacionar o pensar, o agir e sentir, no contexto de uma organização de trabalho, em condições e relações singulares de trabalho (MENDES; FERREIRA, 2008).

O sofrimento é potencializado, sobretudo, pela complexidade das mudanças, sendo estas, muitas vezes, estruturais, com o objetivo de diminuir os custos da organi- 
zação. Essas mudanças, muitas vezes, geram desprazer/insatisfação nos trabalhadores. Para E2 e E3, o momento crítico foi a mudança drástica do modo de trabalhar e a extinção da empresa que trabalhavam. Essas mudanças resultaram em transtornos físicos e comportamentais. A separação das pessoas queridas do trabalho e as dificuldades encontradas na chegada em outras secretarias foram consideradas traumáticas e tristes, sendo esse sofrimento ocasionado pela alteração na organização do trabalho e pelo conflito pessoal interno da possibilidade de corte de vínculos nas relações sociais de trabalho.

Outro contexto de desprazer/insatisfação é a falta de planejamento em longo prazo, a falta de continuidade dos projetos e os retrabalhos gerados com as mudanças dos modelos de gestão. Essas mudanças no ambiente de trabalho, que se mostra incerto, leva o funcionário a conviver com angústia e ansiedade. Para Dejours (1994), esses sentimentos são grandes geradores de sofrimento e assemelham-se à destruição mental.

As mudanças que têm sido implementadas ao longo dos modelos de gestão têm provocado sentimentos de incerteza, preocupação, temor, ansiedade e angústia nos servidores públicos. Esses fatos, para Dejours, Abdoucheli e Jayet (1994), provocam a retenção da energia pulsional do indivíduo, fazendo do trabalho uma fonte de tensão e desprazer. Em razão dessas desestruturações e da instabilidade geradas no ambiente de trabalho, a energia acumulada acaba por aumentar a carga psíquica do trabalhador.

O aumento da carga psíquica, que é definida como o “eco ao nível do trabalhador da pressão que constitui a organização do trabalho” (DEJOURS; ABDOUCHELI; JAYET, 1994, p. 28), foi evidenciado de forma extrema nesta pesquisa. Emergiu, na narrativa, um caso em que a pressão citada pelos autores foi ao nível máximo, em que as mudanças na organização do trabalho ecoaram tão forte que culminaram com uma consequência fatal para um trabalhador.

Na narrativa de E7, isso pode ser verificado pelo relato que ele fez do que aconteceu com o colega de trabalho, que chegou a falecer porque essa pressão psíquica se constituiu de forma desequilibrante na sua relação com o trabalho e com os pares no trabalho. Seu desequilíbrio estava relacionado aos modelos de gestão implantados, que exigiam dele novas formas de trabalhar com as quais não concordava e não admitia como corretas, que mexiam no seu modus operandi e em suas relações sociais no trabalho. Para o trabalhador narrado por E7, foi uma carga tão grande que resultou em uma carga física insuportável, com elevação da pressão arterial e consequente Acidente Vascular Cerebral (AVC), levando-o a óbito no ambiente de trabalho. E7 elaborou isso relacionando à questão da (in)flexibilidade no trabalho e entende que a pressão do trabalho não ecoa em cada um de maneira igual. 
A energia pulsional acumulada no aparelho psíquico gera uma tensão que exige ser descarregada por outras vias. Essa tensão provoca uma série de sofrimentos e deixa os trabalhadores vulneráveis a doenças como o estresse, depressão, alcoolismo, desequilíbrio emocional, entre outras. E5, por exemplo, revelou que teve colegas com problemas de depressão, revolta e desencanto em decorrência de algumas mudanças estruturais na organização. Com o processo de readaptação, alguns servidores não suportaram e pediram afastamento do trabalho e outros ficaram doentes com as situações de mudanças na organização. E6 e E14 expõem o alcoolismo como forma de amenizar as pressões sofridas no trabalho.

No intuito de conseguir lidar com as dificuldades decorrentes do trabalho e não adoecer, os trabalhadores utilizam estratégias de defesa, como: racionalização, conformismo, individualismo, negação, passividade, entre outras (DEJOURS, 1992, 2011). Quando questionados sobre a forma com que lidam com as dificuldades decorrentes das mudanças no trabalho, foi possível perceber, pelos discursos de E10 e de E12, a presença da estratégia de conformismo e da negação, principalmente quando E10 disse que teve seus momentos de não adaptação, mas soube esperar; e E12 falou não ter tido nenhuma resistência, mas dificuldades normais nos processos de mudanças. O ato de "não adaptação" ou "nenhuma resistência” minimizam o incômodo ou sofrimento, decorrente das vivências de trabalho.

As estratégias de defesa são construídas para fazer frente às incertezas, às angústias, à insatisfação e à falta de sentido do trabalho. Elas se caracterizam por condutas de adaptação, de resistência, de conformação, de engajamento e mobilização no trabalho, de aumento da atividade, da intensidade e da carga de trabalho ou, ainda, pela recusa de envolvimento em questões que não dizem respeito ao seu setor especificamente, entre outras (DEJOURS; ABDOUCHELI; JAYET, 1994). E6 e E10 utilizavam as estratégias de adaptação como forma de se proteger dos processos de mudanças advindos da NGP.

Uma das grandes dificuldades de se implementar um processo de mudanças é a resistência. Em muitos casos, as pessoas percebem as mudanças como ameaça à forma já estabelecida de desenvolver o seu trabalho. O medo e a incerteza se estabelecem, e as pessoas passam a apresentar um comportamento de resistência a novas práticas. Para E4, os indivíduos precisam estar sintonizados com as mudanças. É preciso que entendam o porquê de elas serem necessárias, bem como a forma como elas devem ser conduzidas. E6, na sua entrevista, ressaltou que até mesmo uma mudança de chefia pode ocasionar conflitos interpessoais, gerando desconforto entre as equipes 
e suas lideranças. Segundo E12, a perda de benefícios financeiros, como uma gratificação de chefia, também é um elemento que potencializa a resistência.

Os servidores utilizam-se também do boicote para fazer resistência às mudanças da gestão. Relatam que, quando queriam implantar boas práticas em projetos, havia o "boicote” para não dar certo. E11 narrou que a resistência ao novo era razão de muitas reclamações e tentativas de continuar trabalhando da mesma forma.

O isolamento e a conformação também se caracterizam como estratégias de defesa às mudanças que ocorrem nas organizações. São explicitadas quando a pessoa deixa de perceber e de interagir com o seu entorno e se fecha, na tentativa de fugir do novo, do desconhecido. Na concepção de E5, essa fuga traz ainda mais sofrimento e termina por provocar o isolamento social, com a perda de amigos e diminuição da qualidade de vida.

Apesar de as mudanças no ambiente de trabalho, dificuldades de enfrentar os modelos de gestão, insegurança e medo serem os fatores que mais parecem sinalizar a possível emergência do sofrimento entre os entrevistados, eles apontam como motivação geradora de prazer o reconhecimento, a autorealização e a satisfação no trabalho e associam esses aspectos à valorização profissional ligada à capacitação profissional, em uma espécie de raciocínio do tipo: o bom profissional sempre garantirá prazerosamente o seu espaço. Mendes (2007, p. 45) define o reconhecimento como sendo uma dinâmica de "valorização do esforço e do sofrimento investido para a realização do trabalho, que possibilita ao sujeito a construção de sua identidade, traduzida afetivamente por vivência de prazer e de realização de si mesmo.”

Nas entrevistas, foi bastante explicitado o sentimento de valorização e de reconhecimento que os servidores públicos passaram a perceber, com o advento da NGP. Para E3, esse foi um período em que o Estado vivenciou uma época de grande transformação e de investimentos na formação do servidor público, proporcionando um conceito mais técnico, resgatando a imagem do Estado e tornando os servidores públicos diferenciados em várias áreas do governo. Segundo E2, nessa época foram criados novos planos de cargos e carreiras, com o intuito de valorizar os trabalhadores e os funcionários públicos. E1 e E3 reforçaram esse pensamento, afirmando que foram dadas todas as condições para que as pessoas se desenvolvessem profissionalmente, e que foram muitas as oportunidades de capacitação.

Para Dejours (1992) e Mendes (2007), as vivências de prazer se manifestam por meio da gratificação, da realização, do reconhecimento, da liberdade e da valorização no trabalho pela organização, bem como da visualização dos resultados, da realização das tarefas, da descentralização das decisões e da liberdade de expressão. 
Com base nas verbalizações, percebe-se que o orgulho de ser funcionário público era muito grande, principalmente quando se tratava da participação nas mudanças ocasionadas pelos modelos de gestão (E3). E9 ressaltou seu amor pelo serviço público e sua contribuição para a sociedade. A sensação de felicidade vivida por E5 e seus colegas é claramente percebida no avanço e conquistas de sua organização. Para E11 e E12, o bom relacionamento com as pessoas, a continuidade das mudanças e as realizações no trabalho eram vividas pelos servidores com prazer e motivação.

\section{CONCLUSÃO}

As características das mudanças na gestão pública emergiram, neste trabalho, numa perspectiva histórica, desvelando um intenso amálgama entre os modelos de gestão patrimonialista, burocrático e da NGP, gerando implicações para o trabalho e trabalhadores no estado pesquisado.

Esse amálgama dos modelos de gestão, do antigo e do novo, do tradicional e do moderno, que se estabeleceu na gestão das secretarias do estado pesquisado, foi evidenciado pela emergência de um discurso por vezes ainda tradicionalista ao se referir à figura do governante, especialmente no que se refere às mudanças estruturais. Se, por um lado, há uma nova forma de administrar que segue os princípios da NGP, por outro, há uma administração ainda personalista, na qual o governante controla e monitora o modus operandi dos trabalhadores, buscando eficiência, eficácia e efetividade para o alcance dos resultados. Isso, como evidenciado, impactou as relações sociais de trabalho de alguns dos entrevistados, especialmente aqueles ocupantes de cargos de gestão estratégica ou técnicos especializados que, por vezes, viam-se em conflito pessoal referente aos seus saberes de especialistas diante do conflito interpessoal com a figura do governante controlador que parecia prescindir desse saber técnico especializado.

O contexto empírico estudado se revelou permeado de heranças patrimonialistas e (dis)funções burocráticas em meio a práticas gerencialistas. Um resultado importante dessa pesquisa é o silêncio sobre um período predominantemente burocrático na gestão pública do estado pesquisado. Distingue-se, contudo, a emergência de algumas variáveis burocráticas, como a centralização, o controle e a meritocracia, contudo narradas no tempo histórico contemporâneo, ressignificadas sob o ideário da NGP e, em casos específicos, com características eminentemente patrimonialistas. A centralização e o controle, por exemplo, têm se tornado possíveis pela inovação tecnológica, corroborando a ideia de que se assiste, na contemporaneidade, ao crescimento do 
fenômeno nomeado por Stephany Filho (2016) como de burocratização tecnológica. A meritocracia, por sua vez, não emergiu associada ao princípio do profissionalismo próprio à burocracia, como de um conhecimento a priori que deve ser comprovado para que haja o ingresso na "máquina burocrática". Diferentemente, nesta pesquisa a meritocracia emergiu ressignificada, de maneira associada à permanente entrega de resultados, logo, a posteriori. A partir da descrição da história da implantação da NGP no estado pesquisado, conclui-se que não há uma ruptura com os modelos anteriores ou uma revolução paradigmática, mas uma situação de modelos amalgamados ou em sobreposição, tornando-se, no prescrito e no real do trabalho, um palco para emergência de conflitos conceituais e existenciais variados.

A análise das características dos conflitos encontrados nas relações sociais de trabalho em organizações que aderiram à NGP, a partir das lentes da Psicodinâmica do Trabalho, apontou que os conflitos originários da relação sujeito-trabalho e das relações sociais, culturais, profissionais e afetivas que ali se desenrolam compõem uma fonte constante de ansiedade, tensão, inquietação, medo e sofrimento para os entrevistados, ao mesmo tempo que esse mesmo contexto e essas mesmas relações, por vezes conflituosas, são palco da emergência de dimensões associadas ao prazer no trabalho, como valorização, satisfação, reconhecimento, confirmando que os construtos prazer e sofrimento operam no real do trabalho de maneira inter-relacionada.

Nas secretarias pesquisadas, foi identificado que a causa maior de mudanças nas relações sociais de trabalho está ligada às mudanças dos governantes, que, por sua vez, são os tomadores de decisão quanto à implantação de novos modelos de gestão. Enfatizou-se pelos entrevistados que os processos de mudanças gerados pelas transições dos modelos não implicavam, necessariamente, a ruptura de relacionamentos no ambiente de trabalho. Contudo, houve casos específicos de extinções de órgãos que impactaram diretamente as relações de trabalho, tanto pelo distanciamento de antigos companheiros de trabalho, por vezes de uma vida toda, quanto pela necessidade de adaptação a novas relações de trabalho, em novos contextos, fenômeno este sempre antecedido por sensações de desamparo, ansiedade e medo diante das incertezas. Por outro lado, há narrativas de acolhimento nas relações sociais de trabalho, por parte daqueles que recebiam alguns desses servidores advindos de órgãos extintos, indicando, assim, o potencial equilibrante das relações sociais de trabalho para a economia psíquica individual.

Na pesquisa foi destacado por alguns entrevistados que, apesar dos embates e fuxicos, mantinham uma relação harmoniosa com seus pares, subordinados e chefias; não sentiam dificuldades de relacionamento; lutavam para manter o ânimo e 
boas amizades, para seguir com suas atividades, mesmo diante de grandes e desafios a serem superados.

Por outro lado, emergiram conteúdos que destacaram os aspectos negativos nas relações entre os sujeitos. Houve relatos de dificuldades de relacionamentos, como vaidades pessoais, confronto pessoal, competências enaltecidas e embates internos em relação à aceitação de métodos de trabalhos implantados e à forma como eram cobrados. Observou-se, ainda, nas relações sociais de trabalho, a falta de interesse por parte dos mais antigos em relação aos novatos e a falta de respeito às hierarquias, por parte de alguns subordinados, destacando-se a prevalência do individualismo sobre o coletivo. A influência política muito forte na administração pública também foi um dos problemas emergentes.

As situações de conflitos narradas foram diversas, como conflito intenso de valores entre práticas patrimonialistas arraigadas e necessidade de implementar processos mais participativos e democráticos; conflito entre o saber técnico e profissional e interferências e interesses políticos na autonomia dos gestores e técnicos; conflito na disputa por posições; conflito de interesses em razão de apadrinhamento e indicações políticas nos processos da organização do trabalho; conflito de gerações como a causa de problemas no cotidiano de trabalho, muitas vezes prejudiciais ao ambiente laboral; conflito intragrupal com a possibilidade de ruptura de vínculos nas relações sociais de trabalho, em decorrência das mudanças estruturais da organização; e, por fim, conflito interpessoal, gerado pelo clima de instabilidade e insegurança existente entre os servidores.

Discussões provocadas por questões de favores no trabalho foram a causa de conflitos explícitos na relação de trabalho, em que o sujeito, por questões éticas, por estar em desacordo com seu superior pelo que estava acontecendo, recusava-se a executar. Uma inferência possível é que a recorrência de situações dessa natureza pode ser conducente ao sofrimento ético (DEJOURS, 2010), aquele em que o sujeito se vê constrangido a fazer aquilo que não considera correto. Contudo, nessa narrativa, o sofrimento ético foi evitado por uma estratégia de não consentimento do sujeito com aquilo que julgava errado.

Quanto ao sofrimento, os efeitos emocionais (desgaste emocional e tristeza) são acumulados no aparelho psíquico, refletindo diretamente no desenvolvimento dos servidores. O medo das mudanças no ambiente de trabalho destacou-se como uma das principais razões de incômodos no cotidiano dos servidores públicos entrevistados. Essas dificuldades encontradas pelos indivíduos estão diretamente relacionadas ao sofrimento, que é ocasionado por vivências de afetos dolorosos. Para equacionar o 
sofrimento potencializado pela complexidade das mudanças, os servidores públicos provocavam a retenção da energia pulsional, que acabava por aumentar a sua carga psíquica. $\mathrm{O}$ acúmulo no aparelho psíquico, gera nos servidores uma tensão que exige ser descarregada por outras vias. É revelado, então, nas entrevistas, o desgaste físico e psicológico, doenças como estresse, alcoolismo e desequilíbrio emocional, além do caso extremo da morte no trabalho.

Para lidar com essas dificuldades, identifica-se, na narrativa, as seguintes estratégias de defesa: negação, adaptação, resistência, conformação, isolamento e fuga. Destaca-se que apenas uma delas, a resistência, tem um aspecto mais proativo do sujeito. Predominaram as estratégias mais reativas, como que indicando que o equilíbrio psíquico, nesse grupo específico de sujeitos, tende a se manifestar predominantemente por meio do aceite ao que está posto do que pelo enfrentamento diante do novo. Isto, porém, não ocorreu de maneira generalizada, haja vista os casos de resistência pontuados e o que eles significaram para os sujeitos envolvidos: equilibrantes para alguns, desequilibrantes para outros.

Apesar das dificuldades de enfrentar os novos modelos de gestão, da insegurança, do medo e de estratégias de defesa predominantemente reativas, foi possível identificar, nas narrativas, sinais que parecem apontar como motivação geradora de prazer: o reconhecimento, a autorrealização, a motivação e a satisfação no trabalho. Os servidores associam esses aspectos à valorização profissional ligada à capacitação profissional, numa espécie de raciocínio do tipo: o bom profissional sempre garantirá prazerosamente o seu espaço.

Diante dos resultados obtidos nesta pesquisa, conclui-se que a lente teórica da PDT se mostrou apropriada para a compreensão do objeto elegido para estudo, pois permitiu uma análise a partir da escuta ao outro sobre suas elaborações a respeito do vivido no contexto “eu e/no meu mundo de trabalho”. A participação dos servidores públicos como informantes de qualidade, bem como a escolha de impressos, manuscritos, documentos e livros que melhor explicassem a configuração atual da administração pública brasileira permitiram uma análise de conteúdo dos materiais de extrema riqueza e profundidade.

Entende-se que esta pesquisa apresenta contribuições para avanço e aprofundamento de estudos teórico-empíricos que busquem compreender as mudanças em curso na gestão pública, especialmente para pesquisadores que o façam numa perspectiva interdisciplinar, interligando áreas como Gestão Pública, Estudos Organizacionais, Gestão de Pessoas e Relações de Trabalho e Psicodinâmica do Trabalho. Estudos com uma constituição interdisciplinar podem, por exemplo, avançar com in- 
vestigações em torno da reflexão recorrente quanto à pertinência ou não de aplicação dos princípios da gestão privada no contexto público. Ao articular pelas lentes da PDT, uma indagação que ainda pode ser abordada por estudos futuros é: o que se diferencia, nesses dois contextos, no que toca à relação intersubjetiva e psicoafetiva do homem com o seu trabalho?

\section{REFERÊNCIAS}

ABRUCIO, F. L. Trajetória recente da gestão pública brasileira: um balanço crítico e a renovação da agenda de reformas. Revista de Administração Pública, Rio de Janeiro, v. 25, n. 5, p. 67-86, 2007. Disponível em: <http://www.scielo.br/pdf/rap/ v41nspe/a05v41sp.pdf>. Acesso em: 14 ago. 2015.

ANDION, C. Por uma nova interpretação das mudanças de paradigma na administração pública. Cadernos da Escola Brasileira de Administração Pública e de Empresas, Rio de Janeiro, v. 10, n. 1, p. 1-19, mar. 2012. Disponível em: <http:// www.scielo.br/pdf/cebape/v10n1/03.pdf>. Acesso em: 14 ago. 2015.

BRASIL. Ministério da Administração e Reforma do Estado. Plano Diretor da Reforma do Aparelho do Estado. Brasília, DF, 1995.

BRESSER-PEREIRA, L. C. Reforma da nova gestão pública: agora na agenda da América Latina, no entanto. Revista do Serviço Público, ano 53, v. 5, n. 1, jan./mar. 2002.

BRESSER-PEREIRA, L. C. Uma nova gestão para um novo Estado: liberal, social e republicano. Revista do Serviço Público, v. 26, n. 1, jan./mar. 2001.

BUENO, M.; MACÊDO, K. B. A clínica psicodinâmica do trabalho: de Dejours às pesquisas brasileiras. ECOS, v. 2, n. 2, 2012. Disponível em: <www.uff.br/periodicoshumanas/ index.php/ecos/article/download/.../723>. Acesso em: 16 out. 2015.

CARDOSO, M. F. Influência da nova gestão pública sobre políticas de educação superior: um estudo acerca do programa de apoio aos planos de reestruturação e expansão das universidades federais (reuni) no nordeste brasileiro. 2016. 100 p. Tese (Doutorado em Administração)-Universidade Federal do Rio Grande do Norte, Rio Grande do Norte, 2016.

DEJOURS, C.; ABDOUCHELI, E.; JAYET, C. Psicodinâmica do trabalho: contribuições da escola dejouriana à análise da relação prazer, sofrimento e trabalho. São Paulo: Atlas, 1994. 
DEJOURS, C. A loucura do trabalho. 2. ed. São Paulo: Cortez, 1992.

DEJOURS, C. Da psicopatologia à psicodinâmica do trabalho. In: LANCMANN, S.; SZNELWAR, L. I (Org.). Christophe Dejours: da psicopatologia à psicodinâmica do trabalho. 3. ed. Rio de Janeiro: FIOCRUZ, 2011.

DEJOURS, C.; DERANTY, J. F. The centrality of work. Critical Horizons, v. 11, i. 2, p. 167-180, 2010.

DEJOURS, C. Subjetividade, trabalho e ação. Revista Produção, v. 14, n. 3, set./ dez. 2004.

FAORO, R. Os donos do poder: formação do patronato político brasileiro. 3. ed. Rio de Janeiro: Globo, 2001.

GOMES, C. C. P. A subjetividade na gestão de pessoas: estudo exploratório com servidores públicos. 2011. 68 p. Tese (Doutorado em Ciências)-Universidade do Vale do Rio dos Sinos, São Leopoldo, 2011.

GUIMARÃES, T. A. A nova administração pública e a abordagem da competência. Revista de Administração Pública, Rio de Janeiro, v. 3, n. 34, p. 125-140, maio 2000. Disponível em: < bibliotecadigital.fgv.br/ojs/index.php/rap/article/download/6284/4875>. Acesso em: 14 ago. 2015.

HOOD, C. A Public Management For All Seasons? Public Administration, v. 69, p. 3-9, Spring 1991.

LODGE, M.; GILL, D. Toward a new era of administrative reform? The myth of post-NPM in New Zealand. Governance, v. 24, i. 1, p. 141-166, Jan. 2011.

MENDES, A. M; FERREIRA, M. C. Contexto de Trabalho. In: SIQUEIRA, M. M. M. (Org.). Medidas do comportamento organizacional: ferramentas de diagnóstico e gestão. Porto Alegre: Artmed, 2008. p. 111-123.

MENDES, M. M. Vivências de prazer e sofrimento no trabalho de profissionais de uma fundação pública de pesquisa. Psicologia em Revista, v. 20, p. 34-55, 2014.

MENDES, A. M. Pesquisa em psicodinâmica do trabalho: a clínica do trabalho. In: MENDES, A. M. (Org.). Psicodinâmica do trabalho: teoria, método e pesquisas. São Paulo: Casa do Psicólogo, 2007. p. 65-87. 
MERLO, A. R. C.; MENDES, A. M. Perspectivas do uso da psicodinâmica do trabalho no Brasil: teoria, pesquisa e ação. Cadernos de Psicologia Social do Trabalho, São Paulo, v. 12, n. 2, p. 141-156, 2009.

PAES DE PAULA, A. P. Administração Pública Brasileira entre o gerencialismo e a gestão social. Revista de Administração de Empresas, v. 45, p. 36-49, 2005.

PECI, A.; ALCADIPANI, R. Demarcação científica: uma reflexão crítica. In: ENCONTRO NACIONAL DA ASSOCIAÇÃO DOS PROGRAMAS DE PÓS-GRADUAÇÃO EM ADMINISTRAÇÃO, 3., 2004, Curitiba. Anais... Curitiba, 2004.

PIRES, A. P. Amostragem e pesquisa qualitativa: Ensaio teórico e metodológico. In: POUPART, J. et al. (Org.). A pesquisa qualitativa: enfoques epistemológicos e metodológicos. Rio de Janeiro: Vozes, 2008.

SECCHI, L. Modelos organizacionais e reformas da administração pública. Revista de Administração Pública, Rio de Janeiro, v. 2, n. 43, p. 347-369, mar. 2009. Disponível em: <http://www.scielo.br/pdf/rap/v43n2/v43n2a04.pdf>. Acesso em: 16 set. 2015.

SICHÈRE, P. Douleuret travail: quid de la psychodynamique? Questions posées à Isabelle Gernet. Douleurs: Évaluation, Diagnostic, Traitement, v. 11, p. 135-40, 2010.

SILVA, G. R. F.; LAVNCHICHA, G. R. F. A Clínica psicodinâmica do trabalho: teoria e método. Khóra: Revista Transdisciplinar, v. 2, p. 2, 2015.

SIMIONE, A. A. A modernização da gestão e a governança no setor público em Moçambique. Revista de Administração Pública, v. 48, p. 551-570, 2014.

STAKE, R. E. Estudos de caso em pesquisa e avaliação educacional. Educação e Seleção, n. 7, p. 5-14, 2013.

STEPHANY FILHO, L. Burocratização tecnológica em tempos de capitalismo flexível: análise da relação entre Sistemas ERP e o pensamento burocrático. 2016. 87 p. Dissertação (Mestrado em Administração)-Universidade Estadual do Ceará, Fortaleza, 2016.

WEBER, M. Economia e Sociedade: fundamentos da sociologia compreensiva. Revisão Técnica de Gabriel Cohn, Brasília, v. 2, n. 1, 1999. 


\title{
Como citar este artigo:
}

\begin{abstract}
ABNT
AGUIAR, Rafaela Gomes; SANTOS, Ana Cristina Batista dos. Conflitos nas relações sociais de trabalho no contexto da nova gestão pública à luz da psicodinâmica do trabalho. RACE, Revista de Administração, Contabilidade e Economia, Joaçaba: Ed. Unoesc, p.157-184, 2017. Edição Especial. Disponível em: $<$ http://editora.unoesc.edu.br/index.php/race>. Acesso em: dia/mês/ano.

\section{APA}

Aguiar, R. G., Santos, A. C. B. dos. (2017). Conflitos nas relações sociais de trabalho no contexto da nova gestão pública à luz da psicodinâmica do trabalho [E. especial]. RACE, Revista de Administração, Contabilidade e Economia, 157-184. Recuperado em dia/mês/ano, de http://editora.unoesc.edu.br/index.php/race
\end{abstract}

